\title{
Capacity Building for Refugee Mental Health in Resettlement: Implementation and Evaluation of Cross-Cultural Trauma-Informed Care Training
}

\author{
Hyojin $\operatorname{Im}^{1}$ (I) . Laura E. T. Swan ${ }^{1}$
}

Published online: 22 February 2020

(c) Springer Science+Business Media, LLC, part of Springer Nature 2020

\begin{abstract}
Refugee mental health needs are heightened during resettlement but are often neglected due to challenges in service provision, including lack of opportunities for building capacity and partnership among providers. We developed and implemented culturally-responsive refugee mental health training, called Cross-Cultural Trauma-Informed Care (CC-TIC) training. We evaluated CC-TIC, using a free listing and semi-structured retrospective pre- and post-training evaluation with five localities in two states in the U.S. The results showed significant improvement in providers' knowledge of trauma impacts, cultural expressions of trauma/stress-related symptoms, and culturally-responsive trauma-informed care. Trauma-informed care specific to refugee resettlement was regarded as the most helpful topic and community partnership building as the most requested area for future training. This study emphasizes that culturally-responsive trauma-informed approaches can help bridge gaps between mental health care and resettlement services and promote exchanges of knowledge and expertise to build collaborative care and community partnership.
\end{abstract}

Keywords Refugee resettlement $\cdot$ Mental health training $\cdot$ Trauma-informed care $\cdot$ Cultural competence $\cdot$ Retrospective evaluation

\section{Background}

Refugees commonly experience trauma, such as social conflicts and violence, witnessing tragic deaths, torture, forced confinement, and numerous human rights violations [1-3], which likely increases risk for various mental health issues and disorders [3, 4]. In fact, more than one in four refugees who have been exposed to mass conflict report posttraumatic stress disorder (PTSD), and more than one in four report symptoms of major depressive disorder [5]. In a recent review [6], asylum seekers and refugees reported high rates of depression, anxiety, and PTSD (all up to 40\%), despite variation across settings (e.g., displacement or resettlement, high- or low-income countries). In addition, psychiatric disorders are notable when assessment includes mental illness beyond common mental disorders. In a German study

Hyojin Im

him@vcu.edu

1 School of Social Work, Virginia Commonwealth University, 1000 Floyd Ave., 3rd Floor, Richmond, VA 23284, USA with refugees from Syria, Iraq, and Afghanistan, 27\% of those receiving neurological emergency services reported a non-epileptic seizure or psychiatric disorder, which is much higher than the $15 \%$ prevalence in native Germans [7].

Although mental health issues are more prevalent among refugees, mental health care for refugees resettled in the U.S. is sometimes neglected due to multiple challenges in service provision [8]. The concept of mental health care and psychotherapy are foreign in many refugee communities $[9,10]$, and mental health is a stigmatized issue in refugee communities [8-11]. In addition, service providers face challenges related to lack of capacity for culturally-responsive and -relevant services in many refugee-serving agencies. Service providers in human and social services, as well as medical settings, often lack an understanding of refugees' cultural background and unique mental health challenges and needs [12-14]. Additionally, linguistic and cultural barriers keep refugees from accessing mental health services [15]. Refugee mental health interventions are the most effective when they are culturally- and linguistically-sensitive and specific to refugee groups [16]. However, even refugee resettlement agencies, who may be equipped with better cultural and 
linguistic competency than most social or mental health services, struggle to recognize and respond to refugee mental health needs.

Despite these barriers to care, there are few training modules or opportunities that are directly relevant to refugee mental health needs. Two well-known training programs available to refugee-serving professionals are training on the refugee health screener (RHS-15) [17] and mental health first aid training (MHFA) [18]. RHS-15 training is provided to refugee nurses who conduct refugee medical screening and to some refugee resettlement staff for referral purposes. Although this training can help with early detection of common mental disorders (CMDs), the contents are limited to basic screening and do not sufficiently prepare providers to understand and respond to refugee mental health needs. MHFA training has been delivered to refugee community leaders [19] but has limitations in addressing mental health stigma and building hands-on competencies for service providers in the community because it was developed as psychoeducation for those with mental disorders and their caregivers [18]. The curriculum is also not tailored to a refugee population, making it irrelevant or even culturally insensitive when it comes to meeting urgent issues of access to care and stigma. Additionally, many structured training programs including MHFA are costly and dependent on the availability of culturally-competent trainers who understand refugee contexts or acculturative challenges. Sustainable options are needed to ensure that mental health training is affordable and available to refugee service providers in various settings. Given such gaps, the authors developed a tailored training program that helps refugee service providers build competencies related to trauma-informed care in crosscultural settings and community partnerships for referrals and coordination of care. The current study aims to identify refugee service providers' mental health training needs and to evaluate the training program in building competencies and providing tools and resources to refugee-serving professionals and refugee community leaders.

\section{Conceptual Framework}

In order to address the gap in culturally-competent traumainformed care in refugee resettlement services, the first author developed an interactive training curriculum based on Herman's trauma recovery model [20] and Substance Abuse and Mental Health Services (SAMHSA)'s core principles of trauma-informed care [21]. The training curriculum is comprised of two pillars: (1) trauma-informed care and (2) culture-informed care. The trauma-informed pillar is based on the idea that trauma can affect entire refugee communities, and interventions must address this trauma across all types of services and care in the community. The cultureinformed pillar is based on the idea that culture influences refugees' trauma experiences and help-seeking; thus, to provide appropriate mental health care, providers must apply or embed culturally-sensitive supports to their services. Together, these pillars form the cross-cultural traumainformed approach to refugee mental health and wellness, which aims to guide stratified interventions and services for refugees and to build healing partnership among refugeeserving providers.

\section{Methods}

\section{Cross-Cultural Trauma-Informed Care (CC-TIC) Training}

The Cross-Cultural Trauma-Informed Care (CC-TIC) training was developed based on the first author's psychoeducation manual on trauma and culturally-specific, as well as general, mental health topics in the context of refugee resettlement [22]. The training, which was delivered over two consecutive days, consists of eight 1.5-h-long sessions, followed by a one-hour reflection and discussion session. The contents involve knowledge building (e.g., mental health terms, refugee trauma and its sequelae, refugee mental health issues, and cultural expressions of distress) and skill building (e.g., psychoeducation, listening skills, systems of care and multi-tiered intervention, community-based interventions, grounding and mindfulness, and self-care). The training contents were slightly modified for each site to meet unique as well as common needs in each locality. For example, a session on integrated care was included when many healthcare providers attended, while more contents on complex trauma were added when the community recruited providers in school settings and family services. The training was delivered by the first author at five sites in two states, over a two-year period, and was hosted by national agencies responsible for state-wide refugee health promotion programs. One site offered the training twice, once in 2018 and again in 2019 with slightly different topics. Table 1 shows the comprehensive list of training topics per locality. Of note, each locality has different resettlement patterns. When providing the training, the authors aimed to focus on the major refugee ethnic and cultural groups that each site has resettled. Most of the sites have many refugee groups in common, which include Afghan, Bhutanese, Congolese and Karen/Karenni.

\section{Data Collection}

After each CC-TIC training, participants were asked to reflect on the training experience and assess their competencies retrospectively. Retrospective study refers to data collected about interventions or programs that happened 
Table 1 List of training topics per locality

\begin{tabular}{|c|c|c|c|c|c|c|}
\hline & $\begin{array}{l}\text { State \#1, Locality A, } \\
2018\end{array}$ & $\begin{array}{l}\text { State \#1, Locality A, } \\
2019\end{array}$ & $\begin{array}{l}\text { State \#1, } \\
\text { Locality B, } \\
2019\end{array}$ & $\begin{array}{l}\text { State \#2, Locality C, } \\
2018\end{array}$ & $\begin{array}{l}\text { State \#2, } \\
\text { Locality D, } \\
2019\end{array}$ & $\begin{array}{l}\text { State \#2, } \\
\text { Locality E, } \\
2019\end{array}$ \\
\hline \multicolumn{7}{|l|}{ Individualized topics } \\
\hline Interpreters & \multicolumn{6}{|c|}{ Working with interpreters (tips and recommendations) } \\
\hline Complex trauma & \multicolumn{6}{|c|}{$\begin{array}{l}\text { Complex trauma and working with } \\
\text { traumatized children/families }\end{array}$} \\
\hline $\begin{array}{l}\text { Integrated care for the } \\
\text { refugee community }\end{array}$ & $\begin{array}{l}\text { Integrated care for refu- } \\
\text { gee mental health and } \\
\text { psychosocial support }\end{array}$ & & & \multicolumn{3}{|c|}{$\begin{array}{l}\text { Integrated care for refugee mental health and } \\
\text { psychosocial support }\end{array}$} \\
\hline $\begin{array}{l}\text { Trauma-informed care } \\
\text { for refugees }\end{array}$ & $\begin{array}{l}\text { Trauma-informed care } \\
\text { in refugee resettle- } \\
\text { ment }\end{array}$ & & & \multicolumn{3}{|c|}{ Trauma-informed care in refugee resettlement } \\
\hline $\begin{array}{l}\text { Cultural competency } \\
\text { and cultural humil- } \\
\text { ity }\end{array}$ & $\begin{array}{l}\text { A spectrum of cultur- } \\
\text { ally informed care } \\
\text { (from cultural com- } \\
\text { petency to cultural } \\
\text { humility) }\end{array}$ & & & \multicolumn{3}{|c|}{ Cultural competency vs. cultural humility } \\
\hline $\begin{array}{l}\text { Capacity building } \\
\text { for refugee mental } \\
\text { health }\end{array}$ & $\begin{array}{l}\text { Possible ways to build } \\
\text { capacity and partner- } \\
\text { ships for refugee } \\
\text { mental health }\end{array}$ & & & & & \\
\hline \multicolumn{7}{|l|}{ Common topics } \\
\hline $\begin{array}{l}\text { Mental health terms } \\
\text { and refugee trauma }\end{array}$ & \multicolumn{6}{|c|}{$\begin{array}{l}\text { Basic terms related to mental health (ex. stress, trauma, distinction between mental health and mental disorders) } \\
\text { Refugee trauma-pre- and post-migration, resettlement stressors, acculturative stress } \\
\text { Different types of traumas (acute and prolonged trauma) }\end{array}$} \\
\hline $\begin{array}{l}\text { Consequences of } \\
\text { trauma }\end{array}$ & \multicolumn{6}{|c|}{$\begin{array}{l}\text { Consequences of trauma (habits of trauma, multifaceted impacts of trauma on brain, mental health, relationship, } \\
\text { spirituality, and community) }\end{array}$} \\
\hline $\begin{array}{l}\text { Common mental } \\
\text { health issues among } \\
\text { refugees }\end{array}$ & \multicolumn{6}{|c|}{$\begin{array}{l}\text { Common mental disorders in refugee populations (PTSD, depression, anxiety, somatic symptoms, adjustment disor- } \\
\text { ders, behavioral issues-addiction and abuse/misuse) }\end{array}$} \\
\hline $\begin{array}{l}\text { Intersection between } \\
\text { trauma and culture }\end{array}$ & \multicolumn{6}{|c|}{ Cultural influences on mental health expressions and experiences (ex. cultural idioms of distress) } \\
\hline Psychoeducation & \multicolumn{6}{|c|}{ Basic psychoeducation (what or how to say to those in mental health needs) } \\
\hline Listening skills & \multicolumn{6}{|c|}{ Listening skills (deep listening \& active listening, etc.) } \\
\hline $\begin{array}{l}\text { Systems of care: } \\
\text { toward a multi- } \\
\text { tiered model }\end{array}$ & \multicolumn{6}{|c|}{$\begin{array}{l}\text { A multi-tiered model for refugee mental health and psychosocial support (pyramid model of refugee mental health } \\
\text { needs \& services) }\end{array}$} \\
\hline $\begin{array}{l}\text { Community- based } \\
\text { interventions for } \\
\text { refugee newcomers }\end{array}$ & \multicolumn{6}{|c|}{$\begin{array}{l}\text { Importance and examples of community-based interventions } \\
\text { Different formats and ways to provide community-based interventions }\end{array}$} \\
\hline $\begin{array}{l}\text { Self-care and mind- } \\
\text { fulness }\end{array}$ & \multicolumn{6}{|c|}{$\begin{array}{l}\text { Self-Care: Compassion fatigue, burnout and secondary trauma } \\
\text { Grounding and mindful exercises }\end{array}$} \\
\hline Resources & \multicolumn{6}{|c|}{ Resources for trauma-informed and culturally-sensitive care for refugees } \\
\hline
\end{tabular}

in the past [23]. While retrospective designs may introduce bias based on participant recall [24, 25], they can allow for longer observation periods [26], greater generalizability [27], and more cost-efficient data collection [27, 28]. Studies have found that retrospective designs produce adequately valid and reliable results [29-31] and provide information that may be less objectively true but still important [32]. We adopted this methodology as it can allow participants to conscientiously evaluate their baseline knowledge and competencies, especially related to new subject matters, by decreasing the possibility of overestimating baseline understanding [23, 33].

As such, we used retrospective study to assess participants' pre- and post-test knowledge related to refugee mental health and psychosocial support. We embedded this retrospective pre-and post-training evaluation (RPPE) into a mixed-methods design. First, we had participants free list three training needs to explore gaps in capacity for refugee mental health care. Then, we used RPPE to assess participants' knowledge and skills in refugee mental health before 
and after the CC-TIC training. We included seven items measuring core competencies at every site (e.g., refugee trauma and mental health and trauma-informed and cultureinformed care) along with four to five additional topics that were tailored to each training site. Along with the structured RPPE items, we added four open-ended questions, related to the most helpful topical areas, remaining gaps, applicability of the training, and suggestions for future training. The study was exempted from IRB review by the authors' institution as the training evaluation was conducted by the hosting agencies for the purpose of program evaluation and no identifiable information was obtained for the assessment.

\section{Participants}

The CC-TIC training aims to improve mental health competencies for not only mental health professionals (e.g., clinical psychologists/social workers and mental health nurse practitioners/counselors) but also non-mental health care providers, including refugee resettlement staff, public health nurses, school liaisons/coordinators, caseworkers, community health workers, and refugee community leaders, volunteers, and interpreters. Participants self-reported their profession. They were given 12 response options which were then grouped into three categories: (1) mental health provider, (2) refugee resettlement worker, and (3) other [collapsed from the remaining 10 options: healthcare provider (nurse practitioners, physicians, etc.), social services, interpretation, medical liaison/community health worker/ medical case manager, teacher/school social worker/provider in school settings, university researcher, refugee program supervisor (government, state coordinator, etc.), refugee community leader/volunteer, community-based organization, or other]. A total of 175 people registered to attend the training (Locality A: 79 registered; Locality B: 42 registered; Locality C: 16 registered; Locality D: 18 registered; Locality E: 20 registered). While a few individuals who registered for the training did not attend, our estimated number of across-site training attendees is 175. A total of 140 participants completed the free listing exercise (estimated response rate of $80 \%$ ), and 128 participants took the survey (estimated response rate of $73.14 \%$ ), with 120 participants providing complete survey answers (estimated response rate of $68.57 \%$ ). Descriptive statistics are provided in Table 2.

\section{Data Analysis}

The free listing data and open-ended questions were analyzed using conventional content analysis [34]. Participants' responses were grouped into themes and categories, which were compiled to broader domains across the six training localities. For the RPPE data, we ran descriptive statistics including demographic variables and frequencies of evaluation items, followed by a series of $t$ tests, correlations and ANOVAs to determine the average change in pre- and post-test scores according to different professions and former training experiences. All the quantitative analysis was performed in SPSS Win Ver. 24.

\section{Results}

\section{Free Listing of Training Needs}

The free listing data is shown in Table 3. We identified six overarching themes in the training priorities listed by the study participants: (1) refugee interventions and programs, (2) refugee trauma, (3) refugee service resources, (4) refugee resettlement challenges and needs, (5) provider networking, and (6) other. Of the 140 participants, most (83.6\%) listed refugee interventions and programs as one of their top three training priorities. Most participants (56.4\%) also reported learning about refugee resettlement challenges and needs as a training priority. Table 3 also shows subthemes within each of the six themes.

\section{RPPE Data}

The total and individual-item means for the evaluation data are shown in Table 4, along with the $t$ test results and average change in pre- and post-test score. All $t$ tests were significant at the pre-determined cutoff point of 0.05. For the seven core competency items included in the survey for all six localities, the average change in total core competency score was $8.35(t[119]=15.078, p<0.001)$. The pre-test to post-test change in individual core competency score ranged from 0.80 (basic mental health terms) to 1.71 (multi-tiered model for refugee mental health and psychosocial support. Table 4 also shows four of the tailored competencies, each of which was included in at least three localities.

\section{Open-Ended Responses}

Analysis of the four open-ended survey questions revealed a set of themes. The most common theme regarding the most helpful contents $(N=128)$ was refugee trauma and trauma-informed care $(n=56,43.8 \%)$, followed by cultural competency and cultural idioms of distress $(n=40,31.3 \%)$, and partnership building $(n=35,27.3 \%)$. Others reported mental health symptoms and clinical skills $(n=19,14.8 \%)$, self-care $(n=10,7.8 \%)$, and the multi-tiered intervention model $(n=5,3.9 \%)$ as the most beneficial topics. Regarding remaining gaps $(N=128)$, most participants skipped a response or reported that all topics were clear $(n=17$, $13.3 \%)$. Participants requested extended training on community partnership building ( $n=25,19.5 \%)$, trauma recovery 
Table 2 Descriptive analysis of evaluation data, across six sites

\begin{tabular}{|c|c|c|c|}
\hline Variable & Total $N$ & Frequency $(\%)$ & $M(S D)$ \\
\hline Gender & 124 & & \\
\hline Female & & $96(77.4 \%)$ & \\
\hline Male & & $28(22.6 \%)$ & \\
\hline Age (in years) & 77 & & $38.73(10.50)$ \\
\hline Prior experience working with refugees & 88 & & \\
\hline Yes & & $80(90.9 \%)$ & \\
\hline No & & $8(9.1 \%)$ & \\
\hline Time working with refugees (in years) & 115 & & $6.36(5.27)$ \\
\hline Profession $^{\mathrm{a}}$ & 128 & & \\
\hline Mental health service provider & & $37(28.9 \%)$ & \\
\hline Healthcare provider & & $12(9.4 \%)$ & \\
\hline Refugee resettlement services & & $32(25.0 \%)$ & \\
\hline Interpretation & & $14(10.9 \%)$ & \\
\hline Medical liaison/case worker, community health worker & & $12(9.4 \%)$ & \\
\hline Teacher, school social worker, school setting & & $12(9.4 \%)$ & \\
\hline Researcher & & $2(1.6 \%)$ & \\
\hline Refugee program supervisor & & $1(0.8 \%)$ & \\
\hline Refugee community leader/volunteer & & $10(7.8 \%)$ & \\
\hline Community-based organizations & & $11(8.6 \%)$ & \\
\hline Social services & & $22(17.2 \%)$ & \\
\hline Other & & $6(4.7 \%)$ & \\
\hline Locality & 128 & & \\
\hline State \#1, Locality A, 2018 & & $37(28.9 \%)$ & \\
\hline State \#1, Locality A, 2019 & & $29(22.7 \%)$ & \\
\hline State \#1, Locality B, 2019 & & $10(7.8 \%)$ & \\
\hline State \#2, Locality C, 2018 & & $15(11.7 \%)$ & \\
\hline State \#2, Locality D, 2019 & & $18(14.1 \%)$ & \\
\hline State \#2, Locality E, 2019 & & $19(14.8 \%)$ & \\
\hline Felt it enhanced expertise & 74 & & \\
\hline Not at all & & $0(0 \%)$ & \\
\hline Somewhat & & $33(44.6 \%)$ & \\
\hline Substantially & & $41(55.4 \%)$ & \\
\hline Likeliness to recommend training & 75 & & \\
\hline Yes & & $73(97.3 \%)$ & \\
\hline Not sure & & $2(2.7 \%)$ & \\
\hline No & & $0(0 \%)$ & \\
\hline
\end{tabular}

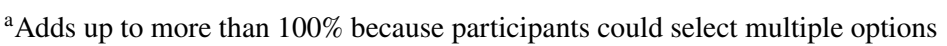

( $n=12,9.38 \%$ ), techniques of mental health assessment and interventions $(n=11,8.6 \%)$, the multi-tiered programs $(n=7,5.5 \%)$, and self-care $(n=2,1.6 \%)$. Analysis of the applicable topics and future training needs are detailed in Table 5.

A series of $t$ tests comparing the average change in pre- and post-test scores by prior mental health training $($ yes $=101$, no $=23$ ) revealed a greater change in total common competency scores $(t[115]=3.070, p=0.003)$ for those without prior mental health training $(M=11.55$, $S D=6.30$ ) than for those with prior mental health training $(M=7.35, S D=5.66)$. The areas of competencies showing the most improvement among those without prior training included: mental health term knowledge $(t[118]=2.917, p=0.004)$, refugee CMD knowledge $(t[119]=2.055, p=0.042)$, psychoeducation knowledge $(t[119]=4.438, p<0.001)$, tiered model knowledge $(t[118]=2.556, p=0.012)$, and trauma-informed knowledge $(t[119]=2.577, p=0.011$.$) . There was no$ significant difference in change in refugee trauma knowledge $(t[119]=1.498, p=0.137)$ or cultural influence knowledge $(t[27.10]=1.669, p=0.107)$ based on prior mental health training. We also did not find meaningful differences in competency scores across localities 
Table 3 Topics of training needs for refugee mental health care and services $(\mathrm{N}=140)$

\begin{tabular}{|c|c|c|c|c|c|c|}
\hline \multirow[t]{3}{*}{ Training needs } & \multicolumn{6}{|c|}{ Frequency by locality } \\
\hline & \multicolumn{2}{|l|}{ State \#1 } & \multicolumn{4}{|l|}{ State \#2 } \\
\hline & $\begin{array}{l}\text { Locality } \\
\mathrm{A}, 2019 \\
(N=57)\end{array}$ & $\begin{array}{l}\text { Locality } \\
\mathrm{B}, 2019 \\
(N=32)\end{array}$ & $\begin{array}{l}\text { Locality } \\
\mathrm{C}, 2018 \\
(N=15)\end{array}$ & $\begin{array}{l}\text { Locality } \\
\mathrm{D}, 2019 \\
(N=19)\end{array}$ & $\begin{array}{l}\text { Locality } \\
\mathrm{E}, 2019 \\
(N=17)\end{array}$ & Total $(N=140)$ \\
\hline Refugee interventions and program & 55 & 17 & 10 & 21 & 14 & 117 \\
\hline Best practices for refugee mental health & 15 & 12 & - & 9 & 6 & 42 \\
\hline Trauma-informed care & 27 & 2 & - & 11 & 5 & 45 \\
\hline Basic clinical skills & 13 & 3 & 1 & 1 & 3 & 21 \\
\hline Refugee trauma & 12 & 12 & 7 & 6 & 1 & 38 \\
\hline Refugee trauma experiences & 4 & 5 & - & 1 & 1 & 11 \\
\hline $\begin{array}{l}\text { Understanding and identifying the impacts of } \\
\text { trauma }\end{array}$ & 8 & 7 & - & 5 & 0 & 20 \\
\hline Refugee service resources & 18 & 6 & 7 & 3 & 10 & 44 \\
\hline $\begin{array}{l}\text { Local resources/referral procedures for refugee } \\
\text { mental health }\end{array}$ & 18 & 6 & 7 & 3 & 10 & 44 \\
\hline Refugee resettlement challenges/needs & 35 & 19 & 7 & 11 & 7 & 79 \\
\hline $\begin{array}{l}\text { Identifying/overcoming resettlement obstacles and } \\
\text { challenges }\end{array}$ & 7 & 4 & - & 3 & 1 & 15 \\
\hline Refugee community needs during resettlement & 3 & 3 & - & 1 & 2 & 9 \\
\hline Cultural competency/impacts of culture & 12 & 7 & 1 & 2 & 3 & 25 \\
\hline $\begin{array}{l}\text { Understanding and overcoming refugee mental } \\
\text { health needs }\end{array}$ & 6 & 4 & 1 & 0 & 1 & 15 \\
\hline Destigmatizing/clients prioritizing mental health & 7 & 1 & - & 5 & 0 & 13 \\
\hline Provider networking & 10 & 10 & 3 & 10 & 3 & 36 \\
\hline Networking and collaborating with other providers & 6 & 6 & - & 5 & 3 & 20 \\
\hline Getting stakeholder/administrative buy-in & 2 & 1 & - & 1 & 0 & 4 \\
\hline Training/leading/sharing information with others & 2 & 3 & 0 & 4 & 0 & 9 \\
\hline Other & 16 & 6 & 3 & 5 & 6 & 36 \\
\hline Interpretation and navigating language barriers & 7 & 3 & 1 & 0 & 1 & 12 \\
\hline Building resilience & 0 & 0 & 2 & 0 & 0 & 2 \\
\hline Avoiding compassion fatigue/burnout & 5 & 2 & 0 & 3 & 0 & 10 \\
\hline Policy impacting refugees & 1 & 0 & 0 & 1 & 0 & 2 \\
\hline Understanding/showcasing refugee strengths & 1 & 0 & 0 & 0 & 2 & 3 \\
\hline Working with refugee children/youth & 2 & 1 & 0 & 1 & 3 & 7 \\
\hline
\end{tabular}

Locality $\mathrm{C}$ was coded differently as it was the earliest data collected and coded. A dash is present where data is not available

except for: (1) site B $(M=22.90, S D=3.76)$, which had a significantly higher total common competency score at pre-test $(F[5,115]=2.626, p=0.027)$ compared to Sites $\mathrm{C}(M=16.07, S D=5.32)$ and $\mathrm{D}(M=15.11, S D=4.65)$ and (2) Site A time $1(M=26.22, S D=3.39)$, which had a significantly higher total common competency score at post-test $(F[5,114]=3.127, p=0.011)$ compared to Site A time $2(M=23.81, S D=3.48)$.

Table 6 shows the results of a series of ANOVAs comparing the average change in pre- and post-test scores by profession. These results indicated that the mean change in score was significantly different for mental health providers when compared to refugee resettlement workers and other professions for all core competency items except for refugee trauma knowledge.

\section{Discussion}

The aim of this study was twofold: (1) evaluation of the effectiveness of refugee mental health training for refugee service providers and (2) exploration of needs and challenges in building competencies for refugee mental health. First, the retrospective self-assessment shows how two-day intensive training can build competencies to help understand and respond to refugee mental health needs. Though mental 
Table 4 Items and mean scores for pre- and post-tests, across sites and competency domains

\begin{tabular}{|c|c|c|c|c|c|}
\hline Item $^{\mathrm{a}}$ & $N$ & Pre-test $M(S D)$ & Post-test $M(S D)$ & $\begin{array}{l}\text { Average change } \\
\text { in score }\end{array}$ & Test statistics \\
\hline Core competencies & 120 & $17.08(5.95)$ & $25.43(2.99)$ & 8.35 & $t(119)=15.078 * * *$ \\
\hline Basic mental health terms & 124 & $3.03(1.05)$ & $3.83(0.44)$ & 0.80 & $t(123)=9.236^{* * *}$ \\
\hline Refugee trauma & 125 & $2.72(1.03)$ & $3.74(0.49)$ & 1.02 & $t(124)=12.062 * * *$ \\
\hline Common mental disorders in refugees & 125 & $2.48(1.06)$ & $3.64(0.56)$ & 1.16 & $t(124)=12.628 * * *$ \\
\hline Cultural influences on mental health & 125 & $2.42(1.02)$ & $3.62(0.63)$ & 1.21 & $t(124)=12.868 * * *$ \\
\hline Basic psychoeducation & 124 & $2.50(1.17)$ & $3.60(0.58)$ & 1.11 & $t(123)=10.868 * * *$ \\
\hline $\begin{array}{l}\text { Multi-tiered model for refugee mental health and } \\
\text { psychosocial support }\end{array}$ & 124 & $1.65(1.17)$ & $3.35(0.71)$ & 1.71 & $t(123)=16.822 * * *$ \\
\hline Trauma-informed care in refugee resettlement & 125 & $2.30(1.16)$ & $3.62(0.58)$ & 1.32 & $t(124)=12.944 * * *$ \\
\hline \multicolumn{6}{|l|}{ Tailored competencies } \\
\hline Listening skills ${ }^{\mathrm{b}}$ & 50 & $2.64(1.05)$ & $3.84(0.37)$ & 1.20 & $t(49)=8.083^{* * *}$ \\
\hline Integrated care ${ }^{c}$ & 86 & $1.80(1.10)$ & $3.43(0.70)$ & 1.63 & $t(85)=13.513 * * *$ \\
\hline Cultural humility $^{\mathrm{c}}$ & 88 & $2.28(1.22)$ & $3.65(0.59)$ & 1.36 & $t(87)=11.256^{* * *}$ \\
\hline Trauma consequences ${ }^{\mathrm{b}}$ & 51 & $2.37(1.10)$ & $3.75(0.48)$ & 1.37 & $t(50)=9.268 * * *$ \\
\hline
\end{tabular}

***Significant at $p<0.001$

${ }^{a}$ For all items, participants were asked to retrospectively rate their awareness and understanding

${ }^{\mathrm{b}}$ Items only included for Localities C, D, and E

${ }^{\mathrm{c}}$ Items only included for Localities A (2018), C, D, E

health professionals reported significantly higher competencies in overall topics prior to the training, the reflective post-training scores showed marginal differences across professions, and non-mental health professionals attained a good level of understanding in mental health topics and foundational skills that are crucial to trauma-informed services. It is also notable that mental health providers often do not receive professional training on trauma-related topics $[35,36]$, let alone specifically on refugee mental health. $\mathrm{T}$ In fact, mental health professionals reported the low baseline scores on refugee CMDs, cultural influences on trauma and mental health outcomes, multi-tiered interventions, and trauma-informed care in this study. Although most participants (79\%) reported previous mental health training, there was no significant difference in preexisting knowledge of how trauma and culture intertwine to shape mental health and refugee CMDs. The amount of previous experience (i.e., time) working with refugees also did not affect training outcomes in core competencies except for self-assessed general confidence prior to the training, which corroborated that work experiences alone do not build competencies in how to respond to refugee mental health needs. This implies significant gaps in currently-available training for refugeeserving professionals and a lack of culturally-responsive and -sensitive mental health training not only for those without mental health backgrounds but also for mental health professionals with formal training and direct practice experience.

This study also sheds light on current needs and challenges in refugee mental health training and proposes future suggestions and strategies for building capacity for traumainformed care for refugees in various service settings. Knowledge and hands-on skills for refugees with mental health needs were of the highest demand, followed by resettlement-related mental health needs and cultural knowledge to provide culturally-responsive and contextually-relevant programs. Reportedly, mental health professionals showed higher competencies in overall mental health knowledge and skills and less understanding of culture-specific needs and resettlement contexts, while refugee resettlement staff and community leaders presented the opposite patterns. Though mental health professionals take a critical role in community capacity for trauma-informed care and refugee mental health services $[37,38]$, the findings of this study also emphasize the importance of collaborative and coordinated care. Participating in the training with a heterogeneous group provided insight into refugee mental health supports and situated individual programs in a broader system of care beyond segmented interventions, also helping to overcome pathologization of normal grieving processes and acculturation distress in the refugee community.

Participants highly valued mutual learning and networking opportunities throughout the CC-TIC training, which corroborates the synergic effects suggested by previous training models to promote interprofessional learning [39] and mutual empowerment through intercultural communication and advocacy $[40,41]$ in community settings. This format promotes a public health approach and the principles of trauma-informed care, which underscores awareness of 
Table 5 Analysis of open-ended questions on applicable topics and future training $(\mathrm{N}=128)$

\begin{tabular}{ll}
\hline Item & Frequency (\%) Quotes
\end{tabular}

Workshop topics that participants plan to apply to their agency or community Trauma responses/trauma-informed care $26(20.3 \%)$

Community partnerships

Teaching coworkers/staff

$16(12.5 \%)$

Cultural competency/population- specific information

Knowledge about refugee trauma experiences

Psychoeducation/community trainings

$11(8.6 \%)$

Mental health knowledge

$10(7.8 \%)$

Community engagement

Sharing workshop resources/exercises

Self-care

Terminology

Listening skills

Resettlement policies

Grounding/mindfulness "the additional knowledge was useful in that it enhanced a deeper understanding of how best to engage and accommodate families and students coping with trauma and resettlement stressors"

"Trauma, stress and mental health"

"As a caseworker, I need to do better about addressing trauma on a daily basis"

"I would like to see our community develop a better network of service providers"

"more partnerships with community"

"I am so very excited about the conversations and cross-agency community-building to come"

"Develop workshop for coworkers, dept., \& agency"

"I supervise 14 therapists-will take info back $\&$ educate them"

"I would love to help provide some of this info to our clinicians in small consistent training to improve the mental health care we provide"

"Become more culturally sensitive; serve clients with the culture-informed lenses"

"I am planning to add contents about Western and non-Western culture scenario into my agency's presentation curriculum"

"A better awareness of the background of refugee trauma"

"Refugee trauma and force migration"

"definitely would love to do some psychoeducation and community wellness workshops with residents/clients. I also want to continue connecting with other service provider"

"I also want to be able to convey that idea to community members in an approachable way that makes them better understand what refugees have gone through and continue to deal with every day"

"common mental disorder in refugee population"

"Integrating the tiers in the process of mental treatment"

"Developing trauma-informed care of my agency and be involved in community capacity"

"Engaging Community"

"Potentially considering how to expand capacity for groups and utilizing training manual for training other staff or partners"

"The stone and flower exercise"

"self care...preventing fatigue"

"Care of self"

"language that I will incorporate during direct care around trauma and stress"

"Trauma terminology"

"I would like to more actively apply the different listening skills that were discussed"

"The exercise of deep listening was very helpful. It was a good reminder that we can soften into the experience and allow the client to simply be witnessed. In a way, it's practicing humility"

"background on resettlement program history"

"improving systems"

$3(2.3 \%) \quad$ "The grounding technique" 
Table 5 (continued)

Item $\quad$ Frequency (\%) Quotes

Translating resources

$2(1.6 \%)$

Topics that participants would like covered in future workshops

Community partnerships

$21(16.4 \%)$

Networking/sharing information

$21(16.4 \%)$

Refugee mental health

Trauma-informed care

$16(12.5 \%)$

Examples/application of learning

Community engagement

Community interventions

Clinical skills

$14(10.9 \%)$

Cultural competency/issues for specific cultures
"A lot of topics that were shared in this workshop can be taught to refugee families, however if I want to give some examples, I would like to translate some of different exercises...into Arabic and Farsi"

"I really want to learn more about how I can provide services to the community and how we all work together collaboratively on mental health"

"More examples of what community partnerships can look like"

"Workshops based on problem solving, community challenges facing some of the subpopulations in [our city] to generate cross-agency action in partnership with community leaders"

"Resources...to make sure we know who to go to about various concerns/needs of the refugee population"

"communicating and networking to share services"

"Resources, community network, knowledge of providers"

"Integrated care for refugee mental health psychosocial support"

"any topic on refugee health"

"Anxiety, depression, trauma"

"Best practices for implementing trauma informed care in a resettlement agency"

"Trauma recovery and healing"

"group work with traumatized refugees/immigrants"

"I would love to have a workshop that would allow open discussions and case studies to apply the knowledge we learned from this workshop to actual practice settings"

"discussing more real life/like life examples could be helpful"

"video/examples of therapy session with interpreter with different techniques"

"How to encourage others to engage more with the refugee community \& seek to be more involved in serving them. Initiating \& sustaining programs...Especially fiscally"

"a training on how to motivate and empower community elders and leaders to continue to practice and share their knowledge and expertise... Their involvements in this area has proven to always play a significant part in strengthening community in may ways"

"community-based interventions, examples of other states"

"I think a cultural competency training for specific populations with teachers and school staff would be an excellent idea and super beneficial for that communication piece"

"Trauma focus therapy for mental health providers"

"Communication skills"

"Clinical interventions for mental health practitioners who work with survivors of war trauma"

"Further information about various cultures; a breakdown of languages, traditions, stigmas, norms, non-verbal/verbal communication, etc"

"Refugee population specific interventions per cultural/ethnic group (e.g., which interventions have been successful for each population)",

"education about specific ethnic/cultural groups" 
Table 5 (continued)

\begin{tabular}{|c|c|c|}
\hline Item & Frequency $(\%)$ & Quotes \\
\hline Vulnerable immigrant/refugees populations & $10(7.8 \%)$ & $\begin{array}{l}\text { "Expanding on childhood response to trauma \& long-term } \\
\text { effects" } \\
\text { "LGBTQ refugees \& how they can be supported" } \\
\text { "Incorporating undocumented survivors experience" }\end{array}$ \\
\hline More in-depth coverage & $7(5.5 \%)$ & $\begin{array}{l}\text { "An advanced training on this topic" } \\
\text { "Future workshops could build further on the knowledge that } \\
\text { [the facilitator] shared. She had to skip over a lot of material } \\
\text { just due to the time constraints involved" } \\
\text { "More in depth discussion of cultural expressions of trauma; }\end{array}$ \\
\hline Bodies' response to trauma & $5(3.9 \%)$ & "How trauma affects physical health" \\
\hline Refugee trauma experiences & $5(3.9 \%)$ & $\begin{array}{l}\text { "Resettlement stories" } \\
\text { "Refugee trauma pre and migration" }\end{array}$ \\
\hline Trauma recovery & $5(3.9 \%)$ & $\begin{array}{l}\text { "Anything that would help refugees overcome their trauma is } \\
\text { welcome" } \\
\text { "Trauma recovery and healing" }\end{array}$ \\
\hline Self-care & $5(3.9 \%)$ & $\begin{array}{l}\text { "self-care" } \\
\text { "Staff trauma and stress management" }\end{array}$ \\
\hline Integrated care & $3(2.3 \%)$ & $\begin{array}{l}\text { "Integrated care for refugee mental health psychosocial sup- } \\
\text { port" }\end{array}$ \\
\hline Grounding/mindfulness & $2(1.6 \%)$ & $\begin{array}{l}\text { "I would have enjoyed more physical/relaxation/grounding } \\
\text { exercises or movement or interactive exercises" }\end{array}$ \\
\hline Potential triggers & $1(0.8 \%)$ & "potential triggers of body language asking questions etc" \\
\hline
\end{tabular}

trauma impacts not only in the refugee community but also among caregivers and service providers and emphasizes collaborative care and partnership building across service sectors to overcome challenges in mental health stigma, cultural and linguistic barriers to services, and other psychosocial issues that obstruct mental health care (e.g., transportation, insurance and eligibility, literacy, etc.) [42]. As previous research points out $[43,44]$ training alone may not suffice to build collaborative care across agencies and service settings. This study shows that capacity-building efforts allow an open platform to discuss common challenges across communities of practice and to reorient gaps in knowledge and skills on an individual level to advocacy and partnership at organizational- and community-levels. Regardless of localities, participants were enthusiastic about the idea of providers' networks or partnership meetings to regularly discuss refugee mental health issues despite such challenges as lacking buy-in or internal supports from leadership, few resources for community-wide action, and limited interagency accountability.

As a naturalistic evaluation study, this research has some limitations to consider. The study was conducted as part of program evaluation by two state-wide refugee health programs and turned into a case study of five resettlement sites with no comparison groups. Follow-up to track how participants retain and utilize training competencies would be beneficial and is the next step of this study. Retrospective measures were efficient in this study due to limited selfawareness on unknown topics (e.g., cultural humility); however, future research may consider adopting a conventional pre- and post-test design to assure improvement in competencies over time. Also, an in-depth study on how partnerships can be built across mental health fields and psychosocial programs would help design an effective community partnership or coalition model addressing common refugee mental health challenges beyond services working in silo.

\section{New Contribution to the Literature}

This study contributes to the field by addressing gaps in knowledge related to mental health training and capacity building in the context of refugee resettlement services. We developed and implemented training on refugee mental health that is culturally sensitive and contextually relevant to service environments, which fills gaps in the field related to lack of appropriate trainings for refugeeserving staff. We have also proposed an innovative training approach that emphasizes mutual learning and partnership building opportunities. The culturally-responsive traumainformed approach helps bridge gaps between mental health care and psychosocial services in current refugee 
Table 6 Items and mean scores by profession, across sites

\begin{tabular}{|c|c|c|c|c|c|}
\hline \multirow[t]{2}{*}{ Item $^{a}$} & \multirow[t]{2}{*}{$N$} & \multicolumn{3}{|l|}{ Score $^{\mathrm{a}}$} & \multirow[t]{2}{*}{ Test statistics } \\
\hline & & $\begin{array}{l}\text { Mental health } \\
\text { provider } M \\
(S D)\end{array}$ & $\begin{array}{l}\text { Refugee resettle- } \\
\text { ment worker } M \\
(S D)\end{array}$ & Other profession & \\
\hline Pre-test total & 121 & $21.34(3.78)$ & $15.26(5.16)$ & $15.41(6.08)$ & $F(2,118)=15.803, p<0.001 * * *$ \\
\hline Basic mental health terms & 125 & $3.68(0.63)$ & $2.67(1.11)$ & $2.82(1.07)$ & $F(2,122)=10.838, p<0.001 * * *$ \\
\hline Refugee trauma & 125 & $3.11(0.91)$ & $2.78(0.75)$ & $2.72(1.03)$ & $F(2,122)=4.934, p=0.009 * *$ \\
\hline Common mental disorders in refugees & 125 & $2.95(1.05)$ & $2.30(0.87)$ & $2.28(1.07)$ & $F(2,122)=5.450, p=0.005^{* *}$ \\
\hline Cultural influences on mental health & 125 & $2.89(0.61)$ & $2.15(1.06)$ & $2.25(1.11)$ & $F(2,122)=6.338, p=0.002 * *$ \\
\hline Basic psychoeducation & 124 & $3.41(0.69)$ & $1.89(1.01)$ & $2.22(1.17)$ & $F(2,121)=22.473, p<0.001 * * *$ \\
\hline $\begin{array}{l}\text { Multi-tiered model for refugee mental health } \\
\text { and psychosocial support }\end{array}$ & 124 & $2.33(1.04)$ & $1.37(1.01)$ & $1.36(1.16)$ & $F(2,121)=10.069, p<0.001 * * *$ \\
\hline Trauma- informed care in refugee resettlement & 125 & $2.94(0.91)$ & $2.07(1.03)$ & $2.03(1.22)$ & $F(2,122)=10.183, p<0.001 * * *$ \\
\hline Post-test total & 120 & $25.86(2.53)$ & $25.22(3.38)$ & $25.28(3.08)$ & $F(2,117)=0.494, p=0.611$ \\
\hline Basic mental health terms & 124 & $3.89(0.39)$ & $3.81(0.40)$ & $3.80(0.48)$ & $F(2,121)=0.526, p=0.593$ \\
\hline Refugee trauma & 125 & $3.73(0.51)$ & $3.81(0.40)$ & $3.70(0.53)$ & $F(2,122)=0.463, p=0.631$ \\
\hline Common mental disorders in refugees & 125 & $3.70(0.57)$ & $3.70(0.47)$ & $3.57(0.59)$ & $F(2,122)=0.833, p=0.437$ \\
\hline Cultural influences on mental health & 125 & $3.68(0.53)$ & $3.56(0.75)$ & $3.62(0.64)$ & $F(2,122)=0.280, p=0.756$ \\
\hline Basic psychoeducation & 124 & $3.73(0.45)$ & $3.52(0.70)$ & $3.57(0.59)$ & $F(2,121)=1.285, p=0.280$ \\
\hline $\begin{array}{l}\text { Multi-tiered model for refugee mental health } \\
\text { and psychosocial support }\end{array}$ & 124 & $3.42(0.65)$ & $3.22(0.89)$ & $3.38(0.66)$ & $F(2,121)=0.630, p=0.535$ \\
\hline Trauma- informed care in refugee resettlement & 125 & $3.66(0.59)$ & $3.62(0.56)$ & $3.59(0.59)$ & $F(2,122)=0.148, p=0.863$ \\
\hline Change in score, total & 120 & $4.51(3.42)$ & $9.96(6.33)$ & $9.91(6.23)$ & $F(2,117)=11.645, p<0.001 * * *$ \\
\hline Basic mental health terms & 124 & $0.22(0.48)$ & $1.15(1.10)$ & $1.00(0.97)$ & $F(2,121)=11.560, p<0.001 * * *$ \\
\hline Refugee trauma & 125 & $0.62(0.72)$ & $1.04(0.81)$ & $1.25(1.04)$ & $F(2,122)=5.431, p=0.005^{* *}$ \\
\hline Common mental disorders in refugees & 125 & $0.76(0.89)$ & $1.41(0.97)$ & $1.30(1.07)$ & $F(2,122)=4.390, p=0.014 *$ \\
\hline Cultural influences on mental health & 125 & $0.78(0.71)$ & $1.41(1.15)$ & $1.38(1.11)$ & $F(2,122)=4.547, p=0.012 *$ \\
\hline Basic psychoeducation & 124 & $0.32(0.53)$ & $1.63(1.15)$ & $1.35(1.16)$ & $F(2,121)=16.378, p<0.001 * * *$ \\
\hline $\begin{array}{l}\text { Multi-tiered model for refugee mental health } \\
\text { and psychosocial support }\end{array}$ & 124 & $1.08(0.87)$ & $1.85(0.99)$ & $1.71(1.19)$ & $F(2,121)=9.003, p<0.001 * * *$ \\
\hline Trauma- informed care in refugee resettlement & 125 & $0.71(0.75)$ & $1.55(1.15)$ & $1.56(1.20)$ & $F(2,122)=7.589, p<0.001 * * *$ \\
\hline
\end{tabular}

$* p<0.05$

$* * p<0.01$

$* * * p<0.001$

${ }^{a}$ Participants self-reported their profession with 12 response options which were then grouped into three categories: (1) mental health provider, (2) refugee resettlement worker, and (3) other (collapsed from the remaining 10 options: healthcare provider, social services, interpretation, medical liaison/community health worker/medical case manager, teacher/provider in school setting, university researcher, refugee program supervisor, refugee community leader/volunteer, community-based organization, or other)

resettlement program, which can promote exchanges of knowledge and expertise to build collaborative care and community partnership.

Acknowledgements We wish to thank all the community partners who supported and organized the refugee mental health training and the program evaluation. This study would not be possible without all the participants who joined the training and shared their valuable opinions and suggestions.

\section{References}

1. Birman D, Tran N. Psychological distress and adjustment of Vietnamese refugees in the United States: association with pre- and postmigration factors. Am J Orthopsychiatry. 2008;78:109-20.

2. Haldane J, Nickerson A. The impact of interpersonal and noninterpersonal trauma on psychological symptoms in refugees: the moderating role of gender and trauma type. J Trauma Stress. 2016;29:457-65. 
3. Mollica R, McInnes K, Pool C, Tor S. Dose-effect relationships of trauma to symptoms of depression and post-traumatic stress disorder among Cambodian survivors of mass violence. Br J Psychiatry. 1998;173:482-8.

4. Neuner F, Schauer M, Karunakara U, Klaschik C, Robert C, Elbert T. Psychological trauma and evidence for enhanced vulnerability for posttraumatic stress disorder through previous trauma among West Nile refugees. BMC Psychiatry. 2004;4:1-7.

5. Steel Z, Chey T, Silove D, Marnane C, Bryant R, Ommeren M. Association of torture and other potentially traumatic events with mental health outcomes among populations exposed to mass conflict and displacement: a systematic review and meta-analysis. JAMA. 2009;302:537-49.

6. Turrini G, Purgato M, Ballette F, Nosè M, Ostuzzi G, Barbui C. Common mental disorders in asylum seekers and refugees: umbrella review of prevalence and intervention studies. Int J Ment Health Syst. 2017;11:1-14.

7. Brinckmann MP, van Noort BM, Leithner C, Ploner CJ. Neurological emergencies in refugees. Front Neurol. 2018;9:1-8.

8. Sentell T, Shumway M, Snowden L. Access to mental health treatment by English language proficiency and race/ethnicity. J Gen Intern Med. 2007;22:289-93.

9. Copelj A, Kiropoulos L. Knowledge of depression and depression related stigma in immigrants from former Yugoslavia. J Immigr Minor Health. 2011;13:1013-8.

10. Majumder P, O'Reilly M, Karim K, Vostanis P. 'This doctor, I not trust him, I'm not safe': the perceptions of mental health and services by unaccompanied refugee adolescents. Int J Soc Psychiatry. 2015;61:129-36.

11. Shannon PJ, Wieling E, Simmelink-McCleary J, Becher E. Beyond stigma: barriers to discussing mental health in refugee populations. J Loss Trauma. 2015;20:281-96.

12. Asgary R, Segar N. Barriers to health care access among refugee asylum seekers. J Health Care Poor Underserved. 2011;22:506-22.

13. Lawrence J, Kearns R. Exploring the "fit" between people and providers: refugee health needs and health care services in Mt Roskill, Auckland. N Z Heal Soc Care Community. 2005;13:451-61.

14. McKeary M, Newbold B. Barriers to care: the challenges for Canadian refugees and their health care providers. J Refug Stud. 2010;23:523-45.

15. Ellis $\mathrm{BH}$, Miller $\mathrm{AB}, \mathrm{Baldwin} \mathrm{H}$, Abdi $\mathrm{S}$. New directions in refugee youth mental health services: overcoming barriers to engagement. J Child Adolesc Trauma. 2011;4:69-85.

16. Murray KE, Davidson GR, Schweitzer RD. Review of refugee mental health interventions following resettlement: best practices and recommendations. Am J Orthopsychiatry. 2010;80:576-85.

17. Hollifield M, Verbillis-Kolp S, Farmer B, et al. The Refugee Health Screener-15 (RHS-15): development and validation of an instrument for anxiety, depression, and PTSD in refugees. Gen Hosp Psychiatry. 2013;35:202-9.

18. Kitchener BA, Jorm AF. Mental health first aid: an international programme for early intervention. Early Interv Psychiatry. 2008;2:55-61.

19. Subedi P, Li C, Gurung A, et al. Mental health first aid training for the Bhutanese refugee community in the United States. Int J Ment Health Syst. 2015;9:1-7.

20. Herman J. Trauma and recovery: the aftermath of violence-from domestic abuse to political terror. New York: Basic Books; 1997.

21. Substance Abuse and Mental Health Services Administration: SAMHSA's concept of trauma and guidance for a trauma-informed approach Rockville; 2014.

22. Im H. Trauma-informed cross-cultural psychoeducation (TICCP): Mental health training for refugee community leaders \& mental health care providers (interactive training manual). Richmond, VA: Virginia Commonwealth University and Virginia Department of Behavioral Health and Developmental Services; 2014.
23. Klatt J, Taylor-Powell E. Synthesis of literature relative to the retrospective pretest design: In: The Joint CES/AEA Conference. Toronto; 2005.

24. Brogger J, Eagan T, Eide GE, Bakke P, Gulsvik A. Bias in retrospective studies of trends in asthma incidence. Eur Respir J. 2004;23:281-6.

25. Drake B, Jonson-Reid M. Social work research methods: from conceptualization to dissemination. London: Pearson; 2008.

26. Abbott KV, Barton FB, Terhorst L, Shembel A. Retrospective studies: a fresh look. Am J Speech-Lang Pathol. 2016;25:157-63.

27. Earle CC, Ayanian JZ. Looking back from death: the value of retrospective studies of end-of-life care. J Clin Oncol. 2006;24:838-40.

28. Arnold R, Kotsanos J, Motheral B, et al. Panel 3: methodological issues in conducting pharmacoeconomic evaluations-retrospective and claims database studies. Value Health. 1999;2:82-7.

29. Brewin CR, Andrews B, Gotlib IH. Psychopathology and early experience: a reappraisal of retrospective reports. Psychol Bull. 1993;113:82-988.

30. Hertzman C, Teschke K, Dimich-Ward H, Ostry A. Validity and reliability of a method for retrospective evaluation of chlorophenate exposure in the lumber industry. Am J Ind Med. 1988;14:703-13.

31. Modestino EJ, Winchester J. A retrospective survey of childhood ADHD symptomatology among adult narcoleptics. J Atten Disord. 2013;17:574-82.

32. Batcho KI, Nave AM, DaRin ML. A retrospective survey of childhood experiences. J Happiness Stud. 2011;12:531-45.

33. Malagon-Maldonado G. Retrospective preevaluation-postevaluation in health design. Health Environ Res Des J. 2016;10:13-22.

34. Hsieh H-F, Shannon SE. Three approaches to qualitative content analysis. Qual Health Res. 2005;15:1277-88.

35. Cook JM, Dinnen S, Rehman O, Bufka L, Courtois C. Responses of a sample of practicing psychologists to questions about clinical work with trauma and interest in specialized training. Psychol Trauma Theory Res Pract Policy. 2011;3:253-7.

36. Courtois CA, Gold SN. The need for inclusion of psychological trauma in the professional curriculum: a call to action. Psychol Trauma Theory Res Pract Policy. 2009;1:3-23.

37. Johansson Blight K, Ekblad S, Lindencrona F, Shahnavaz S. Promoting mental health and preventing mental disorder among refugees in Western countries. Int J Ment Health Promot. 2009;11:32-44.

38. Shannon P, Im H, Becher E, Simmelink J, Wieling E, O'Fallon A. Screening for war trauma, torture, and mental health symptoms among newly arrived refugees: a national survey of US refugee health coordinators. J Immigr Refug Stud. 2012;10:380-94.

39. Gudmundsen AC, Norbye B, Abrandt Dahlgren M, Obstfelder A. Interprofessional student meetings in municipal health servicemutual learning towards a Community of Practice in patient care. J Interprof Care. 2019;33:93-101.

40. Goodkind JR. Promoting Hmong refugees' well-being through mutual learning: valuing knowledge, culture, and experience. Am J Community Psychol. 2006;37:77-93.

41. Bäärnhielm S, Mösko M. Cross-cultural training in mental health care-challenges and experiences from Sweden and Germany. Eur Psychiatry. 2012;27:S70-S7575.

42. Wells K, Miranda J, Bruce ML, Alegria M, Wallerstein N. Bridging community intervention and mental health services research. Am J Psychiatry. 2004;16:955-63.

43. Bäärnhielm S, Edlund AS, Ioannou M, Dahlin M. Approaching the vulnerability of refugees: evaluation of cross-cultural psychiatric training of staff in mental health care and refugee reception in Sweden. BMC Med Educ. 2014;14:1-10.

44. Walden J, Valdman O, Mishori R, Carlough M. Building capacity to care for refugees. Fam Pract Manag. 2017;24(4):21-7.

Publisher's Note Springer Nature remains neutral with regard to jurisdictional claims in published maps and institutional affiliations. 